\title{
The prevalence, characteristics, and factors associated with purchasing Chinese herbal medicine among adults in Taiwan
}

\author{
Chun -Chuan Shih 1,2,3,4 Lu-Hsiang Huang ${ }^{5}$, Chun-Chieh Yeh ${ }^{6,7}$, Hsin-Long Lane ${ }^{1}$, Chang-Ju Hsieh ${ }^{1,8}$, \\ Chin-Chuan Tsai ${ }^{1}$, Li-Wei Lin ${ }^{1}$, Ta-Liang Chen ${ }^{9,10,11+}$ and Chien-Chang Liao 9,10,11,12,13*+
}

\begin{abstract}
Background: The objective of this study was to investigate the prevalence and factors associated with purchasing Chinese herbal medicine (CHM) without a physician's prescription among adults.

Methods: Using data from the 2005 National Health Interview Survey and National Health Insurance, we identified 16,756 individuals aged 20 years and older. Socio-demographic factors, lifestyle, medical services utilization and health behaviors were compared between people with and without a history of purchasing CHM by calculating adjusted odds ratios (ORs) and 95\% confidence intervals (Cls) in a multiple logistic regression analysis.

Results: The one-month prevalence of purchasing CHM without a physician' prescription was $5.2 \%$ in Taiwan. People more likely to purchase CHM included people aged $\geq 70$ years (OR 2.84, 95\% Cl 2.03-3.99), women (OR 1.28, 95\% Cl 1.11-1.48), non-indigenous people (OR 2.61,95\% Cl 1.29-5.30), and people with an illness not receiving medical care (OR 2.69, 95\% Cl 2.19-3.31).

Conclusion: The prevalence of purchasing CHM without a physician's prescription is high in Taiwan and is correlated with factors such as socio-demographics, disease history, and behaviors surrounding the utilization of medical care.
\end{abstract}

\section{Background}

In the past ten years, the use of complementary alternative medicine (CAM) among children and adults in Asian and Western countries has been rising [1-9]. Traditional Chinese medicine (TCM) is one of the most popular forms of CAM and is commonly used by people in Taiwan $[4,5]$. The one-year prevalence of TCM use was as high as $28.4 \%$ in $2001[5,10]$. Increasing use of TCM has also been reported in Western countries [11-13]. The use of and expenditures associated with CAM among adults in the United States increased substantially between 1990 and 1997 [2].

Although the outpatient payments for both TCM and Western medicine have been covered by Taiwan's

\footnotetext{
* Correspondence: jacky48863027@yahoo.com.tw

${ }^{\dagger}$ Equal contributors

${ }^{9}$ Department of Anesthesiology, Taipei Medical University Hospital, 252

Wu-Xing Street, Taipei 110, Taiwan

${ }^{10}$ Department of Anesthesiology, School of Medicine, College of Medicine,

Taipei Medical University, Taipei, Taiwan

Full list of author information is available at the end of the article
}

National Health Insurance since 1995, the purchase of non-prescription medicine in pharmacies is still a common occurrence [12]. With the advent of several reports regarding the nephrotoxic and hepatotoxic effects associated with CHM use [14-16], the purchase of CHM without a physician's prescription has become an important health issue [17]. Purchasing CHM without a physician's prescription may lead to adverse effects from either the CHM itself or because of interactions between the $\mathrm{CHM}$ and biomedical medicines [18-22]. A previous study reported that patients with multiple chronic diseases are the major purchasers of TCM products not covered by Taiwan's National Health Insurance (NHI) program [23]. However, some previous studies provide limited information and are plagued by limitations such as small sample size and selection bias [4, 11-13].

Furthermore, there is a paucity of information describing the characteristics of people who purchase $\mathrm{CHM}$ without a physician's prescription in Taiwan. Using data from the 2005 National Health Interview Survey (NHIS) and $\mathrm{NHI}$, we conducted a cross-sectional study to investigate 
the prevalence and factors associated with the purchase of $\mathrm{CHM}$ without a physician's prescription among adults in Taiwan.

\section{Methods \\ Study design}

In 2005, the National Health Research Institute and the Bureau of Health Promotion of Taiwan conducted the National Health Interview Survey (NHIS) using face-toface questionnaire interviews. The population of Taiwan is approximately 23 million and is distributed throughout 7 cities and 18 counties. The 2005 NHIS included a representative sample of 24,726 interviews from the non-institutional population. The interviewees were all residents, and each interview was performed in the subject's home. All subjects interviewed were selected from the household census. With the standardized face-toface questionnaire interview, the NHIS used a multistage, stratified systematic sampling scheme to interview a nationally representative sample of the population of Taiwan. The response rate was $80.6 \%$ for individual subjects. At the end of the NHIS, the participants were asked for permission to access their NHI records for research purposes. All study participants signed the informed consent to link their information with the NHI claims data to retrieve information on medical service use in 2005. This study analyzed 16,756 study participants aged 20 years and older. Our study was evaluated and approved by the Joint Institutional Review Board of E-DA Hospital (EDA-JIRB-2017002).

\section{Data collection}

Both NHIS data and NHI claims data from 2005 were used in this study. With the written informed consent of eligible NHIS participants that allowed the linking of their NHI data, the 2005 NHIS data were linked to the 2005 NHI claims data. Information about prevalence and frequency of TCM and Western medicine use were drawn from the $2005 \mathrm{NHI}$ data. The core question in this study was "Have you ever purchased Chinese herbal medicine for yourself or your family members without a physician's prescription or advice in the past month?" Socio-demographic data (such as age, gender, education, occupation, family income, ethnicity, religion and marital status) and data on folk therapy, regular health checkups and unhealthy lifestyle (including smoking, alcohol use, and betel nut chewing) were derived from the NHIS data.

\section{Definitions and measures}

In Taiwan, TCM includes Chinese herbal medicine, acupuncture, moxibustion, bone reduction (setting a broken bone without surgery), traditional trauma treatment, traditional dislocation treatment, traditional fracture treatment, Tuina (massage and kneading), Baguan (cupping or vacuum bottle therapy), and other therapies. TCM practitioners are registered TCM physicians and practice in a hospitals or clinics. TCM in Taiwan is legal, and TCM physicians can advertise the medical benefits of TCM according to medical law in Taiwan [5]. Chinese herbal medicine is the theory of traditional Chinese herbal therapy, which was the majority of treatments in TCM. Acupuncture is one of forms of TCM in which very thin needles are inserted into some specific points of body. Moxibustion is also one of forms of traditional Chinese medicine therapy which burning dried mugwort on some specific points of the body.

Folk therapy use is defined as the utilization of folk therapy within the past month. The types of folk therapy studied include Gua Sha (skin scraping), Tuina (massage and kneading), Baguan (vacuum bottle therapy), bone setting, spine alignment, Qigong, divination, written charms, shaman consultation, talismans, incense ash, and other related therapies. The difference between TCM and folk therapy lies in their legality. Legislation from the Department of Health in Taiwan has declared that folk therapy practitioners cannot claim any medical benefits from folk therapy. Folk therapy practitioners do not have certifications or legal licenses, and they do not work in clinical settings in Taiwan. For the Western countries, TCM and folk therapy were included in the CAM. However, TCM and folk therapy were different in Taiwan because their legality.

We calculated the density of TCM physicians (TCM physicians $/ 10,000$ persons) using the number of TCM physicians per 10,000 persons for each of the administrative units. The first, second, and third tertiles were considered areas of low, moderate, and high TCM physician density, respectively [5, 24]. A high prevalence of cigarette smoking, alcohol drinking, and betel quid chewing has been found in Taiwan [25]. People with a habit of smoking tobacco (included some periods of smoking in a lifetime, or less than 5 packs in a lifetime, or more than 5 packs in a lifetime), drinking alcohol (current drinkers and any type of alcohol drinks) and/or chewing areca were considered to be engaging in unhealthy lifestyles that are associated with cancer and other diseases $[4,5]$.

\section{Statistical analysis}

In the study, chi-square tests were used to compare the difference in socio-demographic factors, lifestyles, and medical care behaviors between people with and without $\mathrm{CHM}$ use. Fisher's exact test was used when the sample size was small. We used multivariate logistic regression analysis to analyze the factors of TCM and Western medicine use associated with $\mathrm{CHM}$ and estimated the odds ratio (OR) and corresponding 95\% confidence 
Table 1 Characteristics of people with and without purchasing CHM

\begin{tabular}{|c|c|c|c|c|c|c|c|c|}
\hline & \multicolumn{4}{|c|}{ Purchase of CHM } & \multirow[b]{3}{*}{$p$-value } & & & \multirow[b]{3}{*}{ Score } \\
\hline & \multicolumn{2}{|c|}{ No $(N=15,889)$} & \multicolumn{2}{|c|}{ Yes $(N=867)$} & & \multicolumn{2}{|c|}{ Multivariate adjusted } & \\
\hline & $\mathrm{n}$ & (\%) & $\mathrm{n}$ & (\%) & & $\overline{\mathrm{OR}}$ & $(95 \% \mathrm{Cl})^{\mathrm{c}}$ & \\
\hline \multicolumn{9}{|l|}{ Age, years } \\
\hline $20-29$ & 3561 & $(97.8)$ & 81 & (2.2) & \multirow[t]{6}{*}{$<0.0001$} & 1.00 & (reference) & 0 \\
\hline $30-39$ & 3331 & (95.8) & 145 & (4.2) & & 1.87 & $(1.42-2.48)$ & 2 \\
\hline $40-49$ & 3469 & $(93.8)$ & 230 & $(6.2)$ & & 2.71 & $(2.06-3.55)$ & 4 \\
\hline $50-59$ & 2394 & $(93.0)$ & 179 & $(7.0)$ & & 2.82 & $(2.10-3.77)$ & 4 \\
\hline $60-69$ & 1566 & (93.0) & 118 & $(7.0)$ & & 2.80 & $(2.02-3.88)$ & 4 \\
\hline$\geq 70$ & 1568 & (93.2) & 114 & (6.8) & & 2.84 & $(2.03-3.99)$ & 4 \\
\hline \multicolumn{9}{|l|}{ Gender } \\
\hline Male & 8166 & (95.5) & 382 & (4.5) & \multirow[t]{2}{*}{$<0.0001$} & 1.00 & (reference) & 0 \\
\hline Female & 7723 & $(94.1)$ & 485 & (5.9) & & 1.28 & $(1.11-1.48)$ & 1 \\
\hline \multicolumn{9}{|l|}{ Occupation } \\
\hline White collar & 5821 & (92.5) & 276 & $(7.5)$ & \multirow[t]{3}{*}{0.02} & & & - \\
\hline Blue collar & 5828 & (93.9) & 336 & (6.1) & & - & - & - \\
\hline Others & 4284 & (93.4) & 255 & (6.6) & & - & - & - \\
\hline \multicolumn{9}{|l|}{ Education, years } \\
\hline 0 & 1158 & $(92.8)$ & 90 & $(7.2)$ & \multirow[t]{4}{*}{$<0.0001$} & 1.25 & $(0.90-1.73)$ & 1 \\
\hline $1-9$ & 5350 & (93.0) & 404 & $(7.0)$ & & 1.46 & $(1.18-1.80)$ & 1 \\
\hline $10-12$ & 4555 & (95.9) & 194 & $(4.1)$ & & 1.03 & $(0.83-1.27)$ & 1 \\
\hline$\geq 13$ & 4826 & (96.4) & 179 & (3.6) & & 1.00 & (reference) & 0 \\
\hline \multicolumn{9}{|l|}{ Family income, NTDs } \\
\hline$<30,000$ & 4106 & (93.5) & 287 & (6.5) & \multirow[t]{3}{*}{$<0.0001$} & & & - \\
\hline $30,000-200,000$ & 11,360 & (95.3) & 556 & (4.7) & & - & - & - \\
\hline$>200,000$ & 423 & $(94.6)$ & 24 & (5.4) & & - & - & - \\
\hline \multicolumn{9}{|l|}{ Marital status } \\
\hline Married & 10,115 & $(94.2)$ & 626 & $(5.8)$ & \multirow[t]{3}{*}{$<0.0001$} & - & - & - \\
\hline Unmarried & 3965 & $(97.5)$ & 101 & (2.5) & & - & - & - \\
\hline Others & 1809 & $(92.8)$ & 140 & $(7.2)$ & & & & - \\
\hline \multicolumn{9}{|l|}{ Ethnicity } \\
\hline Non-indigenous & 15,532 & $(93.2)$ & 857 & (6.8) & \multirow[t]{2}{*}{0.012} & 2.61 & $(1.29-5.30)$ & 4 \\
\hline Indigenous & 401 & (96.1) & 10 & (3.9) & & 1.00 & (reference) & 0 \\
\hline \multicolumn{9}{|l|}{ Density of physicians ${ }^{a}$} \\
\hline Low & 5657 & (94.3) & 342 & (5.7) & \multirow[t]{3}{*}{0.0002} & 1.16 & $(0.97-1.37)$ & 1 \\
\hline Moderate & 5351 & (95.3) & 365 & $(4.7)$ & & 1.38 & $(1.16-1.65)$ & 1 \\
\hline High & 4881 & (94.9) & 260 & (5.1) & & 1.00 & (reference) & 0 \\
\hline Unhealthy lifestyles $^{\mathrm{b}}$ & & & & & & & & \\
\hline None & 7824 & (93.5) & 442 & (5.4) & 0.4785 & - & - & - \\
\hline One & 3575 & (93.0) & 181 & $(4.8)$ & & & & - \\
\hline Two or three & 4490 & $(93.0)$ & 244 & $(5.2)$ & & & - & - \\
\hline Medical care in past 6 months & & & & & & & & \\
\hline Without illness & 4974 & $(97.0)$ & 156 & (3.0) & $<0.0001$ & 1.00 & (reference) & 0 \\
\hline Illness with medical care & 7409 & $(94.2)$ & 453 & (5.8) & & 1.83 & $(1.52-2.21)$ & 2 \\
\hline Illness without medical care & 3506 & (93.2) & 258 & (6.8) & & 2.69 & $(2.19-3.31)$ & 4 \\
\hline
\end{tabular}

CHM Chinese herbal medicine, TCM traditional Chinese medicine

$1.5 \leq \mathrm{OR}<2.0$ predicted score $=2,2.0 \leq \mathrm{OR}<2.5$ predicted score $=3,2.5 \leq \mathrm{OR}<3.0$ predicted score $=4,3.0 \leq \mathrm{OR}<3.5$ predicted score $=5,3.5 \leq \mathrm{OR}<4.0$ predicted $\mathrm{score}=6$

interval (CI). These covariates included age, gender, family income, ethnicity, marital status, unhealthy lifestyle, folk therapy and density of TCM physicians. For each covariate, we assigned a predicted score as a risk index according to the significant adjusted OR, and the predicted score is proportional to the OR. Purchasing 
predictive score was defined as follows: when $1.0 \leq \mathrm{OR}$ $<1.5$, the purchasing predicted score was 1 , when $1.5 \leq \mathrm{OR}<2.0$, the purchasing predicted score was 2 , when $2.0 \leq \mathrm{OR}<2.5$, the purchasing predicted score was 3 , and when $2.5 \leq \mathrm{OR}<3.0$, the purchasing predicted score was 4. All analyses were performed using Statistical Analysis Software (SAS), version 9.2 (SAS Institute Inc., Cary, North Carolina, U.S.A.). A two-sided $p$-value less than 0.05 was considered significant.

\section{Results}

Among the 16,756 participants aged 20 years and older (Table 1), the one-month prevalence of purchasing $\mathrm{CHM}$ was $5.2 \%$. A higher percentage of older people ( $\geq 70$ years) purchased CHM than other age groups, and more females than males purchased CHM. A higher percentage of participants who were non-indigenous and who were ill with or without medical care in the past six months compared with those without illness purchased CHM. The two groups were comparable in terms of marital status, employment status, family income and educational level. In the multivariate logistic regression analysis, the following individuals were more likely to purchase CHM: females, people aged 40-49, 50-59 or 6069 years old, non-indigenous people, people who had one or two or more unhealthy lifestyles, people who lived in areas where the density of practitioners was high and people who were ill with or without medical care in the past six months.

After adjustment, those more likely to purchase $\mathrm{CHM}$ included individuals who purchased biomedical medicine without a prescription and those who had received emergency care, hospital care or outpatient care in the past year (Table 2).

The use of folk therapy and TCM use in the past year were associated with purchasing CHM (Table 3). In addition, the frequency and expenditure of TCM use were also factors associated with the purchase of CHM. In Table 4 , we divided the predictive scores into six groups $(0-4,5,6,7,8$, and 9$)$, and the $0-4$ group was considered as the comparison group in the analysis. The

Table 2 Medical care and western medicine use for people with and without purchasing CHM

\begin{tabular}{|c|c|c|c|c|c|c|c|}
\hline & \multicolumn{4}{|c|}{ Purchase of $\mathrm{CHM}$} & \multirow[b]{3}{*}{$p$-value } & \multirow{2}{*}{\multicolumn{2}{|c|}{ Multivariate }} \\
\hline & \multicolumn{2}{|c|}{ No $(N=15,889)$} & \multicolumn{2}{|c|}{ Yes $(N=867)$} & & & \\
\hline & $\mathrm{n}$ & (\%) & $\bar{n}$ & (\%) & & $\overline{\mathrm{OR}}$ & $(95 \% \mathrm{Cl})^{\mathrm{b}}$ \\
\hline \multicolumn{8}{|c|}{ Purchase of biomedical medicine ${ }^{a}$} \\
\hline No & 13,172 & $(95.4)$ & 632 & (4.6) & $<0.0001$ & 1.00 & (reference) \\
\hline Yes & 2717 & $(92.0)$ & 235 & (8.0) & & 1.60 & $(1.36-1.88)$ \\
\hline \multicolumn{8}{|c|}{ Emergency care in past year } \\
\hline No & 13,721 & $(95.0)$ & 723 & $(5.0)$ & 0.0137 & 1.00 & (reference) \\
\hline Yes & 2168 & $(93.8)$ & 144 & $(6.2)$ & & 1.17 & $(0.97-1.42)$ \\
\hline \multicolumn{8}{|c|}{ Hospitalized care in past year } \\
\hline No & 14,265 & $(95.0)$ & 759 & $(5.0)$ & 0.0352 & 1.00 & (reference) \\
\hline Yes & 1624 & $(93.8)$ & 108 & $(6.2)$ & & 1.09 & $(0.87-1.35)$ \\
\hline \multicolumn{8}{|c|}{ Outpatient care by WM in past year ${ }^{a}$} \\
\hline No & 4893 & $(95.1)$ & 255 & $(4.9)$ & 0.3900 & 1.00 & (reference) \\
\hline Yes & 10,996 & $(94.7)$ & 612 & $(5.3)$ & & 1.09 & $(0.93-1.27)$ \\
\hline \multicolumn{8}{|c|}{ Frequency of outpatient care by WM in past year } \\
\hline None & 4899 & $(95.1)$ & 255 & $(4.9)$ & $<0.0001$ & 1.00 & (reference) \\
\hline Low & 3739 & $(96.2)$ & 149 & (3.8) & & 0.92 & $(0.74-1.14)$ \\
\hline Moderate & 3645 & $(94.7)$ & 203 & $(5.3)$ & & 1.14 & $(0.94-1.38)$ \\
\hline High & 3606 & $(93.3)$ & 260 & $(6.7)$ & & 1.18 & $(0.98-1.41)$ \\
\hline \multicolumn{8}{|c|}{ Expenditure of WM in past year } \\
\hline None & 4899 & (95.1) & 255 & $(4.9)$ & $<0.0001$ & 1.00 & (reference) \\
\hline Low & 3681 & $(96.2)$ & 147 & (3.8) & & 0.92 & $(0.74-1.14)$ \\
\hline Moderate & 3619 & $(94.5)$ & 210 & (5.5) & & 1.18 & $(0.97-1.43)$ \\
\hline High & 3690 & (93.5) & 255 & (6.5) & & 1.14 & $(0.95-1.38)$ \\
\hline
\end{tabular}

CHM Chinese herbal medicine, WM Western medicine

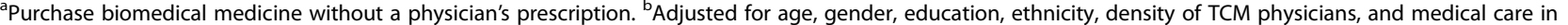
the past 6 months in multiple logistic regression 
Table 3 Medical care visit of TCM for people with and without purchasing CHM

\begin{tabular}{|c|c|c|c|c|c|c|c|}
\hline & \multicolumn{4}{|c|}{ Purchase of $\mathrm{CHM}$} & \multirow[b]{3}{*}{$p$-value } & \multirow{2}{*}{\multicolumn{2}{|c|}{ Multivariate }} \\
\hline & \multicolumn{2}{|c|}{ No $(N=15,889)$} & \multicolumn{2}{|c|}{ Yes $(N=867)$} & & & \\
\hline & $\mathrm{n}$ & (\%) & $\bar{n}$ & (\%) & & $\overline{O R}$ & $(95 \% \mathrm{Cl})^{\mathrm{a}}$ \\
\hline \multicolumn{8}{|c|}{ Use of TCM in past year } \\
\hline No & 11,952 & $(95.1)$ & 610 & $(4.9)$ & \multirow[t]{2}{*}{0.0070} & 1.00 & (reference) \\
\hline Yes & 3937 & $(93.9)$ & 257 & $(6.1)$ & & 1.26 & $(1.08-1.47)$ \\
\hline \multicolumn{8}{|c|}{ Use of TCM in past year } \\
\hline No & 11,952 & $(95.1)$ & 610 & $(4.9)$ & \multirow[t]{4}{*}{0.0071} & 1.00 & (reference) \\
\hline 1 times & 1192 & $(94.2)$ & 73 & $(5.8)$ & & 1.26 & $(0.98-1.63)$ \\
\hline 2 times & 673 & $(94.5)$ & 39 & $(5.5)$ & & 1.13 & $(0.81-1.59)$ \\
\hline$\geq 3$ times & 2072 & $(93.5)$ & 145 & $(6.5)$ & & 1.29 & $(1.07-1.56)$ \\
\hline \multicolumn{8}{|c|}{ Use of folk therapy } \\
\hline No & 14,872 & $(95.2)$ & 743 & $(4.8)$ & \multirow[t]{2}{*}{$<0.0001$} & 1.00 & (reference) \\
\hline Yes & 1012 & $(89.2)$ & 123 & $(10.8)$ & & 2.23 & $(1.82-2.74)$ \\
\hline \multicolumn{8}{|c|}{ Visits of TCM in past year } \\
\hline No & 11,952 & $(95.1)$ & 610 & $(4.9)$ & \multirow[t]{4}{*}{0.0073} & 1.00 & (reference) \\
\hline Low & 1865 & $(94.3)$ & 112 & $(5.7)$ & & 1.22 & $(0.98-1.50)$ \\
\hline Moderate & 1119 & $(93.4)$ & 79 & $(6.6)$ & & 1.35 & $(1.06-1.73)$ \\
\hline High & 953 & $(93.5)$ & 66 & $(6.5)$ & & 1.23 & $(0.94-1.60)$ \\
\hline \multicolumn{8}{|c|}{ Expenditure of TCM in past year } \\
\hline No & 11,952 & $(95.1)$ & 610 & $(4.9)$ & \multirow[t]{4}{*}{0.0152} & 1.00 & (reference) \\
\hline Low & 1276 & $(94.2)$ & 78 & $(5.8)$ & & 1.25 & $(0.97-1.59)$ \\
\hline Moderate & 1320 & $(93.7)$ & 89 & $(6.3)$ & & 1.31 & $(1.04-1.66)$ \\
\hline High & 1339 & $(93.8)$ & 89 & $(6.2)$ & & 1.20 & $(0.95-1.52)$ \\
\hline
\end{tabular}

CHM Chinese herbal medicine, TCM traditional Chinese medicine

${ }^{a}$ Adjusted for age, gender, education, ethnicity, density of TCM physicians, and medical care in the past 6 months in the multivariate logistic regression

predictive scores 5, 6, 7, 8, 9 were highly associated with purchasing CHM.

\section{Discussion}

Using the data from the NHIS and NHI, we found that the one-month prevalence of purchasing CHM without a physician's prescription in adults was 5.2\%. Furthermore, the likelihood of purchasing CHM was associated

Table 4 Predictive scores of purchasing CHM without physician's prescription

\begin{tabular}{cccccc}
\hline \multicolumn{7}{c}{ Purchasing CHM } \\
\cline { 3 - 6 } & $\mathrm{n}$ & Events & Prevalence & OR & $(95 \% \mathrm{Cl})$ \\
\hline Purchasing predictive scores & & & \\
$0-4$ & 8437 & 255 & $3.00 \%$ & 1.00 & (reference) \\
5 & 1683 & 98 & $5.82 \%$ & 1.99 & $(1.57-2.53)$ \\
6 & 1751 & 115 & $6.56 \%$ & 2.27 & $(1.80-2.86)$ \\
7 & 1671 & 110 & $6.58 \%$ & 2.27 & $(1.80-2.86)$ \\
8 & 1685 & 156 & $9.26 \%$ & 3.29 & $(2.67-4.40)$ \\
9 & 1493 & 133 & $8.91 \%$ & 2.87 & $(2.31-3.57)$ \\
\hline \multicolumn{7}{c}{ CHM Chinese herbal } \\
\hline
\end{tabular}

with socio-demographic factors, disease history, and utilization of medical care.

The results of this study showed that women and middle-aged individuals (30-59 years old) have a higher prevalence of purchasing CHM. These findings are similar to results from previous investigations that reported a correlation between age and gender and selfmedication [26-28]. Compared with the elderly, younger people are more knowledgeable about medical care and have a better attitude towards and practice of using medical services [29]. A previous study also suggested that young people are more likely to seek treatment to improve their well-being and disease-related symptoms than older people [30]. Our results suggest that because middle-aged people are generally the primary caregivers in a family, they may be more likely to purchase medicine for their children or parents. In this study, gender was also found to be an important factor associated with purchasing CHM. Women may be more willing to address their health problems by trying multiple therapies not covered by the insurance system. In addition, social networking makes it easier for women to access CHM than men [31]. 
In the present study, we found that participants who were non-indigenous and living in areas with a moderate density of physicians had a higher likelihood of purchasing CHM. In general, residents in urban areas have more access to medical services than rural residents because more physicians practice in cities than in rural areas [32]. Therefore, people living in areas with a high density of TCM physicians have more opportunities to access conventional and unconventional therapies [8]. Explanations of why ethnicity differences exist are complex. Ethnicity covers many factors such as culture, nationality and religion and is also closely associated with socioeconomic status, which affects the accessibility to care, health status, and other predictors of conventional healthcare use $[27,33]$. Therefore, it is important to determine if ethnic differences in folk therapy use emerge or persist when several of these predictors are considered simultaneously. Participants with a greater number of unhealthy behaviors were also more likely to use folk therapy. Shih et al. [12] suggested that individuals who engage in more unhealthy behaviors may consider folk therapy as a form of preventive medicine that can protect their health.

Many people choose to use an alternative therapy based on a recommendation from someone who has used the therapy and has been satisfied with the results. These referrals come mainly from family members, friends, acquaintances, and co-workers [11]. In addition, when an individual has more resources such as money, time, convenience, and access to TCM, the individual's behavioral intention will be stronger. Previous studies have shown that income level is an important factor influencing people to seek alternative care [12]. According to a British study, older people have fewer financial resources to pay for private CAM [14]. Similarly, CAM users tend to have moderate to high incomes [15]. Some studies have reported that most unconventional medicine users are older people with high incomes $[16,18,23]$. We also found that older people purchase TCM products more often than young people, although the influence of personal income on TCM purchasing behavior was not significant. One possible reason that older people's income did not predict purchasing behavior is that the influence of usable resources on behavioral intention should take into consideration not only personal income but also the total family income and other various enabling components. For example, older people have more time and ability to make decoctions from TCM herbs. Several decades ago, TCM was the main therapy in Taiwan, so most senior people have experience making decoctions from TCM herbs. Older people also tend to have more free time. As a result of these factors, the TCM purchasing behavior of the elderly is higher than that of younger individuals.
This study has several limitations. First, recall bias may exist because our data are based on self-reported questionnaires. Second, due to the cross-sectional study design, we could not provide information about whether purchasing CHM without a physician' prescription is increasing or decreasing over time. Additionally, the causal relationship between purchasing $\mathrm{CHM}$ and associated factors cannot be confirmed in this cross-sectional study. Third, because purchasing CHM is a dichotomous variable, information on the dosage, frequency and expenditure is not available.

\section{Conclusions}

In conclusion, purchasing CHM without a physician's prescription in adults is common in Taiwan and is associated with socio-demographics, disease history, and utilization of medical care. Importantly, this study may alert TCM physicians that purchasing CHM without a physician's prescription is a serious problem in Taiwan and requires considerable attention.

\section{Abbreviations \\ CAM: complementary alternative medicine; $\mathrm{CHM}$ : Chinese herbal medicine: $\mathrm{Cl}$ : confidence interval; NHI: National Health Insurance; NHIS: National Health Interview Survey; OR: odds ratio; TCM: traditional Chinese medicine}

\section{Acknowledgments \\ This study is based in part on data obtained from the National Health Insurance Research Database provided by the Bureau of National Health Insurance, Ministry of Health and Welfare, and managed by the National Health Research Institutes. The interpretation and conclusions contained herein do not represent those of the Bureau of National Health Insurance, Ministry of Health and Welfare, or National Health Research Institutes.}

\section{Funding}

This research was supported in part by the Committee on Chinese Medicine and Pharmacy, Department of Health, Taiwan (CCMP98-RD-038; CCMP99-RD035), Taiwan's Ministry of Science and Technology (MOST105-2629-B-038-001; MOST104-2314-B-038-027-MY2; MOST103-2320-B-214-010-MY2), and Taiwan's Ministry of Health and Welfare Clinical Trial and Research Center of Excellence (MOHW105-TDU-B-212-133,019).

\section{Availability of data and materials}

All data supporting the study is presented in the manuscript or available upon request from the first author of this manuscript (Chun-Chuan Shih) at Email: hwathai@seed.net.tw

\section{Authors' contributions}

All authors contributed substantially toward the design of the study, the analysis and interpretation of the data, drafting and revising the manuscript. All authors approved the final version.

\section{Competing interests}

The authors declare that they have no competing interests.

\section{Consent for publication}

All authors have read and agreed to all the contents for publication.

\section{Ethics approval and consent to participate}

This study is based in part on data from the 2001 NHIS approved by the Bureau of Health Promotion, Department of Health and National Health Research Institutes. The Bureau of Health Promotion, Department of Health obtained written informed consent from eligible NHIS participants. The data were analyzed anonymously and all clinical investigations were conducted according to the principles expressed in the Declaration of Helsinki. It was 
not necessary to gain permission from the curators of the database in order to access it for the purposes of our study. Our study was evaluated and approved by the Joint Institutional Review Board of E-DA Hospital (EDA-JIRB2017002).

\section{Publisher's Note}

Springer Nature remains neutral with regard to jurisdictional claims in published maps and institutional affiliations.

\section{Author details}

'The School of Chinese Medicine for Post-Baccalaureate, I-Shou University, Kaohsiung, Taiwan. ${ }^{2}$ Program for the Clinical Drug Discovery from Botanical Herbs, Taipei Medical University, Taipei, Taiwan. ${ }^{3}$ Taipei Chinese Medical Association, Taipei, Taiwan. ${ }^{4}$ Quality of Traditional Chinese Medicine and Pharmacy Medical Association, Taipei, Taiwan. ${ }^{5}$ Clinical Informatics and Medical Statistics Research Center, Chang Gung University, Taoyuan, Taiwan. ${ }^{6}$ Department of Surgery, China Medical University Hospital, Taichung, Taiwan. ${ }^{7}$ Department of Surgery, University of Illinois, Chicago, IL, USA. ${ }^{8}$ Department of Chinese Medicine, Changhua Christian Hospital, Changhua, Taiwan. ${ }^{9}$ Department of Anesthesiology, Taipei Medical University Hospital, 252 Wu-Xing Street, Taipei 110, Taiwan. ${ }^{10}$ Department of Anesthesiology, School of Medicine, College of Medicine, Taipei Medical University, Taipei, Taiwan.

${ }^{11}$ Anesthesiology and Health Policy Research Center, Taipei Medical University Hospital, Taipei, Taiwan. ${ }^{12}$ School of Chinese Medicine, College of Chinese Medicine, China Medical University, Taichung, Taiwan. ${ }^{13}$ Department of Anesthesiology, Shuan Ho Hospital, Taipei Medical University, New Taipei City, Taiwan.

\section{Received: 4 October 2016 Accepted: 11 March 2017}

Published online: 27 March 2017

\section{References}

1. Boon HS, Olatunde F, Zick SM. Trends in complementary/alternative medicine use by breast cancer survivors: comparing survey data from 1998 and 2005. BMC Womens Health. 2007;7:4.

2. Wang CC, Kennedy J, Wu CH. Alternative therapies as a substitute for costly prescription medications: results from the 2011 National Health Interview Survey. Clin Ther. 2015;37:1022-30.

3. Italia S, Brand H, Heinrich J, Berdel D, von Berg A, Wolfenstetter SB. Utilization of complementary and alternative medicine (CAM) among children from a German birth cohort (GINIplus): patterns, costs, and trends of use. BMC Complement Altern Med. 2015;15:49.

4. Shih CC, Su YC, Liao CC, Lin JG. Patterns of medical pluralism among adults: results from the 2001 National Health Interview Survey in Taiwan. BMC Health Serv Res. 2010;10:191.

5. Shih CC, Lin JG, Liao CC, Su YC. The utilization of traditional Chinese medicine and associated factors in Taiwan in 2002. Chin Med J. 2009;122:1544-8.

6. Nahin RL, Barnes PM, Stussman BJ. Expenditures on complementary health approaches: United States, 2012. Natl Health Stat Rep. 2016;95:1-11.

7. Tindle HA, Davis RB, Phillips RS, Eisenberg DM. Trends in use of complementary and alternative medicine by US adults: 1997-2002. Altern Ther Health Med. 2005;11:42-9.

8. Shih CC, Huang LH, Lane HL, Tsai CC, Lin JG, Chen TL, Yeh CC, Liao CC. Use of folk therapy in Taiwan: a nationwide cross-sectional survey of prevalence and associated factors. Evid Based Complement Alternat Med. 2015;2015:649265.

9. Cooper KL, Harris PE, Relton C, Thomas KJ. Prevalence of visits to five types of complementary and alternative medicine practitioners by the general population: a systematic review. Complement Ther Clin Pract. 2013;19:214-20.

10. Chang LC, Huang N, Chou YJ, Lee CH, Kao FY, Huang YT. Utilization patterns of Chinese medicine and western medicine under the National Health Insurance Program in Taiwan,a population-basedstudy from 1997 to 2003. BMC Health Serv Res 2008:8:170.

11. Burke A, Upchurch DM, Dye C, Chyu L. Acupuncture use in the United States: findings from the National Health Interview Survey. J Altern Complement Med. 2006;12:639-48.

12. MacPherson $\mathrm{H}$, Sinclair-Lian $\mathrm{N}$, Thomas K. Patients seeking care from acupuncture practitioners in the UK: a national survey. Complement Ther Med. 2006:14:20-30.

13. Upchurch DM, Burke A, Dye C, Chyu L, Kusunoki Y, Greendale GA. A sociobehavioral model of acupuncture use, patterns, and satisfaction among women in the United States, 2002. Womens Health Issues. 2008;18:62-71.
14. Isnard Bagnis C, Deray G, Baumelou A, Le Quintrec M, Vanherweghem JL. Herbs and the kidney. Am J Kidney Dis. 2004:44:1-11.

15. Vanherweghem JL, Tielemans C, Abramowicz D, et al. Rapidly progressive interstitial renal fibrosis in young women: association with slimming regimen including Chinese herbs. Lancet. 1993;341:387-91.

16. Yuen MF, Tam S, Fung J, Wong DK, Wong BC, Lai CL. Traditional Chinese medicine causing hepatotoxicity in patients with chronic hepatitis B infection: a 1-year prospective study. Aliment Pharmacol Ther. 2006;24:1179-86.

17. Kim JH, Chung CH, Lau CH, Goggins WB, Lau JT, Griffiths SM. Adverse events and poisoning from over-the-counter traditional Chinese medicine: a population-based survey. Hong Kong Med J. 2016;22(Suppl 2):S23-8.

18. Zuo Z, Huang M, Kanfer I, Chow MS, Cho WC. Herb-drug interactions: systematic review, mechanisms, and therapies. Evid Based Complement Alternat Med. 2015;2015:239150.

19. Izzo AA, Ernst E. Interactions between herbal medicines and prescribed drugs: an updated systematic review. Drugs. 2009;69:1777-98.

20. Kim JH, Kwong EM, Chung VC, Lee JC, Wong T, Goggins WB. Acute adverse events from over-the-counter Chinese herbal medicines: a population-based survey of Hong Kong Chinese. BMC Complement Altern Med. 2013;13:336.

21. Al-Ramahi R, Jaradat N, Shalalfeh R, Nasir S, Manasra Y, Shalalfeh I, Esam Y. Evaluation of potential drug- herb interactions among a group of Palestinian patients with chronic diseases. BMC Complement Altern Med. 2015;15:221

22. Zhong LL, Zheng G, Da Ge L, Lin CY, Huang T, Zhao L, Lu C, Lu AP, Bian ZX. Chinese herbal medicine for constipation: zheng-based associations among herbs, formulae, proprietary medicines, and herb-drug interactions. Chin Med. 2016;11:28

23. Liao HL, Ma TC, Chiu YL, Chen JT, Chang YS. Factors influencing the purchasing behavior of TCM outpatients in Taiwan. J Altern Complement Med. 2008:14:741-8.

24. Liao CC, Li TC, Lin RS, Sung FC. Urban and difference in prevalence and incidence of stroke in 2000 in Taiwan. Taiwan J Public Health. 2006;25:223-30.

25. Liao CC, Wang HY, Lin RS, Hsieh CY, Sung FC. Colorectal and prostate cancer screening practices among men in Taiwan. Taiwan J Public Health. 2005:24:209-16.

26. Lukovic JA, Miletic V, Pekmezovic T, et al. Self-medication practices and risk factors for self-medication among medical students in Belgrade, Serbia. PLoS One. 2014;9:e114644.

27. Shandra CL, Sonalkar N. Health self-care in the United States. Public Health. 2016;138:26-32

28. Carrasco-Garrido P, Hernández-Barrera V, López de Andrés A, JiménezTrujillo I, Jiménez-García R. Sex-differences on self-medication in Spain. Pharmacoepidemiol Drug Saf. 2010;19:1293-9.

29. Astin JA. Why patients use alternative medicine: results of a national study. JAMA. 1998;279:1548-53.

30. Hildreth KD, Elman C. Alternative worldviews and the utilization of conventional and complementary medicine. Sociol Inq. 2007;77:76-103.

31. Liu CY, Liu JS. Socioeconomic and demographic factors associated with health care choices in Taiwan. Asia Pac J Public Health. 2010;22:51-62.

32. Blenkinsopp A, Bradley C. Patients, society, and the increase in self medication. Br Med J. 1996;312:629-32.

33. Nwasuruba $C$, Khan M, Egede LE. Racial/ethnic differences in multiple selfcare behaviors in adults with diabetes. J Gen Intern Med. 2007;22:115-20.

\section{Submit your next manuscript to BioMed Central and we will help you at every step:}

- We accept pre-submission inquiries

- Our selector tool helps you to find the most relevant journal

- We provide round the clock customer support

- Convenient online submission

- Thorough peer review

- Inclusion in PubMed and all major indexing services

- Maximum visibility for your research

Submit your manuscript at www.biomedcentral.com/submit
) Biomed Central 